\title{
Landuse and land cover dynamics in the Volta River Basin surrounding APSD forest plantation, Ghana
}

\author{
Addo Koranteng ${ }^{1}$, Isaac Adu-Poku ${ }^{2}$,Tomasz Zawita-Niedźwiecki ${ }^{3}$ \\ ${ }^{1}$ Kumasi Technical University, Institute of Research, Innovation and Development, Kumasi, Ghana, \\ e-mail:dr.adokay@gmail.com \\ ${ }^{2}$ Kwame Nkrumah University of Science and Technology, Geomatic Engineering Department, Kumasi, Ghana \\ ${ }^{3}$ Coordination Centre for Environmental Projects, Bitwy Warszawskiej 1920 r. 3, 02-362 Warszawa, Poland
}

\section{Abstract}

Forest plantation is reckoned to accounts for $7 \%$ of total global forest cover and has the potential to provide $75 \%$ of the global industrial round wood supply. The study analyzed forest resource use trend, mapped out areas of high biodiversity conservation, and made recommendations to promote and sustain large-scale plantation development against the background of anthropogenic pressure on vulnerable ecosystems and biodiversity management.

The methodology adopted for the study involved the application of geographic information system (GIS) and remote sensing techniques, field survey and community interactions. Major findings of the assessment include substantial land use/land cover conversion from one category to another within the past 20 years as a result of agricultural expansion, urbanisation, charcoal production and wood fuel harvesting; dense woodland and riverine forest experienced decline for the 20 -year period whilst agriculture open woodland/grassland and settlement were appreciated; floral diversity was high in the dense woodlands with low regeneration potential because of persistent annual wildfires; significant socio-economic and environmental impacts resulting in the conversion of woodlands and removal of riverine vegetation leading to drying out of streams; charcoal production and shifting cultivation leading to decrease in soil productivity and poor crop yields that promotes poverty amongst the inhabitants.

\section{KeY WORDS}

remote sensing, deforestation, socio-economic trends, anthropogenic pressure

\section{INTRODUCTION}

Forests in the tropics are railing under several economic, political and social pressures because these are being converted for agricultural and infrastructure development and tropical timber production (Stephens et al. 2016). Declining tropical forest area, resulting in a de- creasing native timber stock, exacerbated by growing demand for timber products have made it necessary to invest in plantation forests, thus becoming a progressively vital component of the world's forested lands (FAO 2011; Barlow et al. 2018). Plantation forests constitute only a minimal share of global forest area (Brown and Ball 2000; Lele 2017). Forest plantation is estimated 
to accounts for $7 \%$ of total global forest cover, and has the prospect to provide $75 \%$ of the global industrial round wood supply, wood biomass production, soil and water conservation and wind protection; is key sources of fuel wood and non-timber forest products (Carnus et al. 2003; FAO 2010, 2015).

The world's perception of tree plantations, to a certain extent, is vague. Even though planting few trees is commonly reckoned to be good for the environment, planting shed load of trees increases anxieties amongst naturalists and conservationists. These concerns are premised on plantations often being used to compensate for bad forestry practices. Irrespective of one's view, plantations have a genuine place in the sustainable management of forests because of their importance to meet a wide spectrum of social, economic and environmental objectives (Paquette and Messier 2010).

In Ghana, the African Plantations for Sustainable Development (APSD), a privately owned plantation, has embarked on industrial tree/energy plantation development, which is aimed at generating energy from biomass of Acacia and Eucalyptus species. This project has also the purpose of slowing down the advancement of the desert into transitional zone, biodiversity loss and soil carbon loss. In addition, it is intended to offer employment opportunities to the local communities in order to improve their living standards in this area that is bedevilled with poor infrastructural development, which includes but not limited to roads, schools, hospitals and others.

\section{Problem Statement}

The conversion of natural woodland in the study area is very dramatic but has not been assessed and documented. Unsustainable agricultural practices in the study area have led to the conversion of natural woodland into agricultural fields that have resulted in biodiversity loss and ecological landscape alteration. Moreover, vegetable cultivation in the dry season along the river banks has contributed to the loss of riparian vegetation endangering the ecosystem. In addition, charcoal production in the area has significantly increased because of high charcoal demand by the urban population. It has led to loss of natural woodlands, which acts as carbon sinks, and the consequent emission of greenhouse gases into the atmosphere, which aggravates the effects of climate change on mankind.

\section{Objectives}

The study was undertaken to provide environmental and socio-economic information within a spatial framework

- To develop land use and land use change maps for the area with emphasis on the analysis of land use trend for a period of 20 years.

- To identify and mark major landscape, ecological sensitive area and areas of high value conservation forest as well as potential ecotourism sites.

- To develop biodiversity hotspot/areas of high conservation value with their management regimen to preserve the biodiversity within the framework of scientific research and indigenous knowledge.

\section{Methodology}

\section{Description of study area}

The study area, Figure 1 and 2, is located within latitudes $7^{\circ} 30^{\prime} \mathrm{N}$ and $8^{\circ} 15^{\prime} \mathrm{N}$ and longitudes $0^{\circ}$ and $1^{\circ} \mathrm{W}$. It falls within Atebubu-Amantin, Sene West and East District Assemblies (also a small area of Pru District). It falls within the Volta River Basin and covers about $424,000 \mathrm{ha}\left(424 \mathrm{~km}^{2}\right)$. According to the 2010 Population and Housing Census report, it has the lowest population growth of about $2.3 \%$ with a vast expanse of arable lands and inadequate infrastructural development (GSS 2010). The area falls between the wet semi-equatorial and tropical continental climatic regions of Ghana. The vegetation is predominantly Guinea Savanna Woodland; however, there is remnant natural forest (dry semideciduous fire zone type) that is prone to wildfires.

\section{Materials and data}

\section{Materials}

- Handheld GPS (GARMIN62C)

- Digital camera

- Satellite Images (five ALOS scenes in 2010, three Landsat scenes in1990)

- Aerial photo2010

- Maps (Topographic maps of 1976, Contours 1976 survey, Roads in 2010)

\section{Software}

Software such as ERDAS Imagine 2010, ArcGISv.2010, Google Earth and MS Excel were used in this study. 


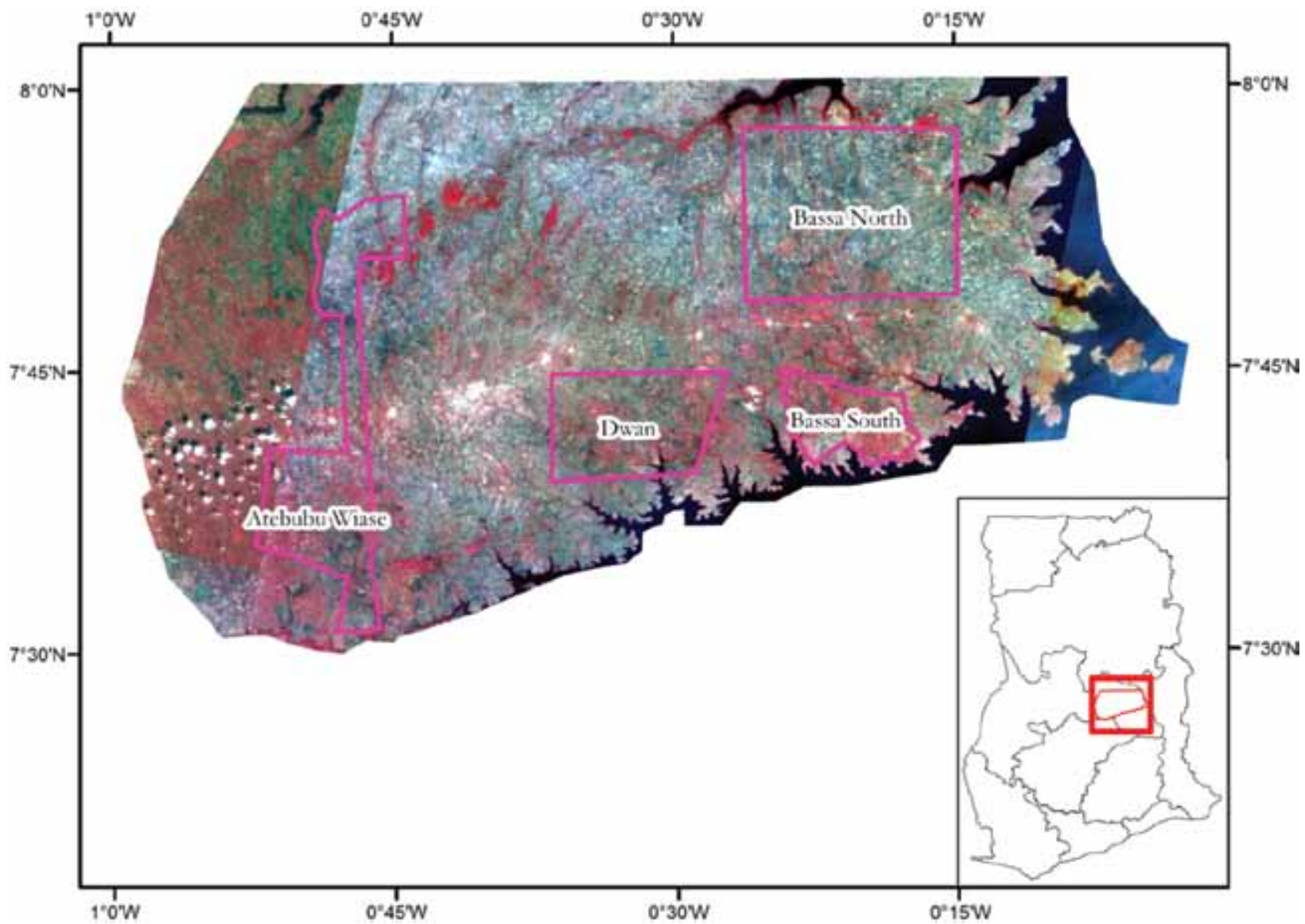

Figure 1. Study area also indicating the APSD concessions

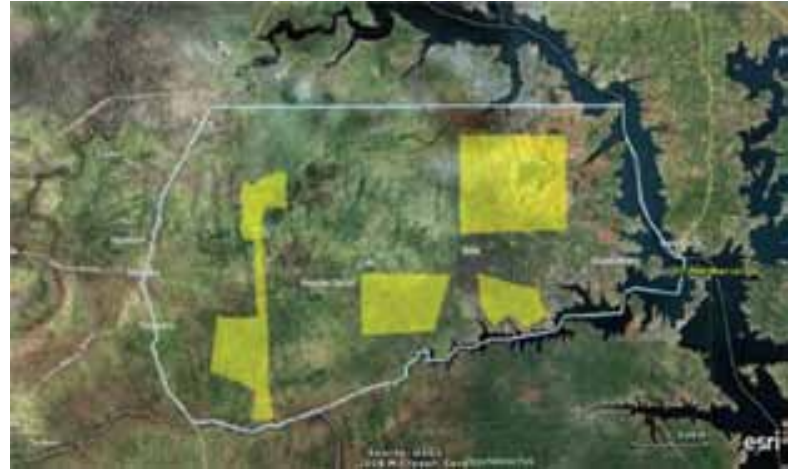

Figure 2. Image of study area (source APSD)

\section{Data Processing}

Desktop review of data was carried out to assemble all available data on the project area. The various maps of the study area, aerial photographs and satellite images were studied and converted to GIS format for integration with other relevant data. The outline of the study area is shown in grey in Figure 2. This map was obtained from APSD in an image format and was geo-referenced to its exact position on the ground with respect to the national grid (Ghana). The boundary of the study area was digitised to extract the study area into GIS vector file format. This was then used as the area of interest to subset satellite images for the 2 time series (epochs). Figure 2 shows the extracted satellite image of study area.

The flow chart in Figure 3 illustrates the steps adopted in achieving the objectives and outputs of the study. It has been structured into four main steps: field data collection, image processing, change analysis and geo-processing analysis in GIS environment. The detailed steps are elaborated in the various subsections, thereafter.

\section{Land use description}

- Dense woodland: This is a natural forest with more than $100 \mathrm{stems} / \mathrm{ha}$. The trees have short stems and profuse branching with a diameter varying from 10 
to $50 \mathrm{~cm}$. They occur in patches and show evidence of burning.

- Open woodland: It consists of short, scattered trees in degraded areas that are interspersed with grass undergrowth and bark of the trees show fire scars.

- Riverine forest: This is a natural forest with closed canopy mostly occurring in strips along rivers and streams and some wetlands.

- Cropland: It consists of fallow areas and grass/crop mosaic mainly annual crops such as maize, cassava, yam and vegetables.

- Settlement and bare surface: It consists of areas that have been populated with permanent residents or covered with scanty grass and exposed rocks and bare lands.

- Water: It consists of stagnant water, lakes and rivers.

\section{Development of landuse map}

\section{Image pre-processing}

From the flow chart in Figure 3, five ALOS scenes for 2010 epoch and three Landsat scenes covering the study area were pre-processed (geo-referenced and re-

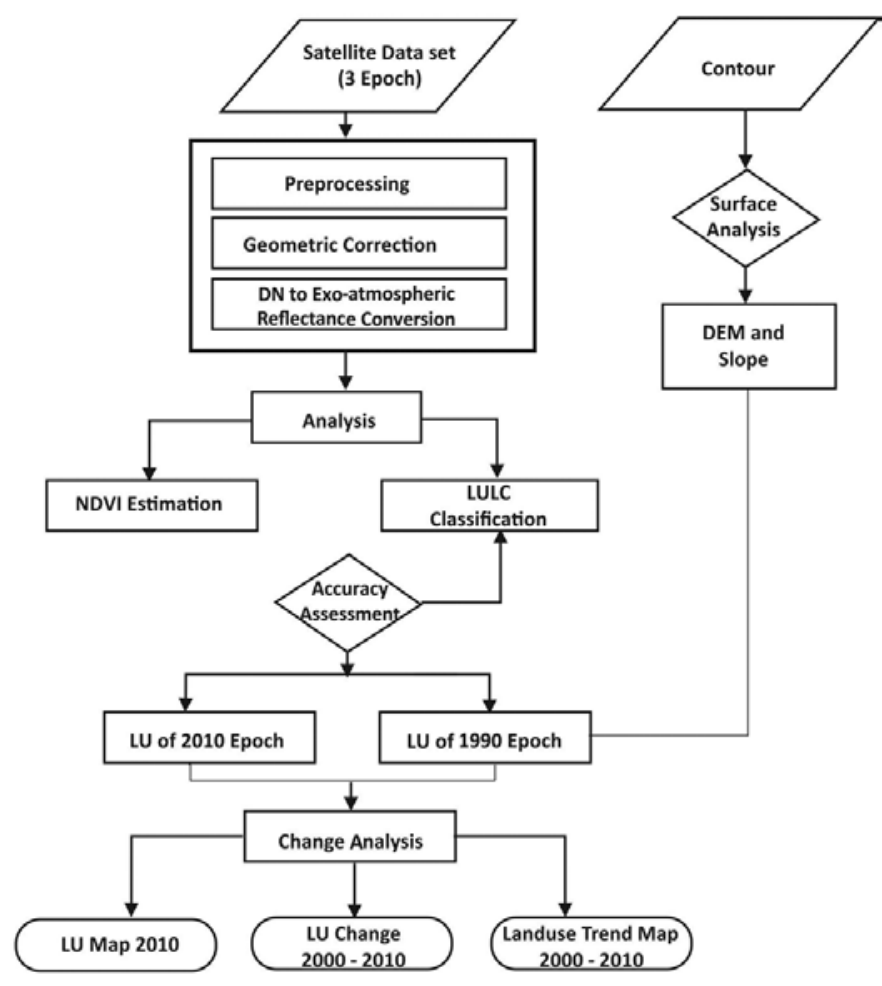

Figure 3. Flow chart of methods projected) to the national grid. For the various epochs (1990 and 2010), the individual scenes were clipped using the study area boundary to get the image of the two epochs.

Normalized Difference Vegetation Index (NDVI), which involves the use of band 3 and band 4, was extracted from the various clipped image expressed in Equation 1:

$$
\mathrm{NDVI}=\frac{\text { Band } 4-\text { Band } 3}{\text { Band } 4+\text { Band } 3}
$$

This ratio is used to differentiate vegetation from non-vegetation as well as grasses from trees. The NDVI image combined with field data and aerial photographs increased the accuracy of the classification significantly.

\section{Field data collection}

The study area was subdivided into grids and numbered serially for easy sampling and identification of sample areas. The road network of the study area was digitised from aerial photographs and overlaid on the sampling frame. The training sites were randomly selected using the aerial photographs as the training classes, and in addition, the NDVI generated was also helpful in the site selection because it differentiates vegetated and non-vegetated areas. During the fieldwork, 10-25 training classes per land cover/land use type were collected depending on the variability in the locality and ecological sensitivity.

\section{Image classification}

The field data were imported in Microsoft Excel and then divided into two sets: 100 classes were used as the training data and 100 as validation data. For 2010 epoch, the training data combined with the NDVI image and fore-knowledge about the area as shown in the flow chart were used to run supervised classification using maximum likelihood classifier. The individual classified scenes for the various parts were later mosaic to obtain the 2010 land use map. A $3 \times 3$ majority filter was applied to the resultant mosaicked file to remove the 'saltand-pepper' effect associated with image classification. The resultant image was passed through clump and eliminate tools in ERDAS Imagine to remove and use fragments less than 0.4 of a hectare. The 2010 classified map was field validated 
and combined with the aerial photographs to classify the 1990 Landsat scenes. According to Tims (2009), orthophotos have proved to be useful when acting as reference for the developing land use and base map.

Same steps elaborated for classifying the $2010 \mathrm{ep}$ och were adopted to obtain the 1990 mosaicked land use map. In all, six land use classes were adopted for the study area in conformity with Intergovernmental Panel on Climate Change (IPCC) criteria for land use and land use change and forestry (LULUCF) definitions.

\section{Accuracy assessment of the classification}

Li et al. (2018) posit that accurate classifications are vital to guarantee precise change-detection results. The validation data of 100 points were used to assess the accuracy of the 2010 land use map by using Error/Confusion matrix. It yielded $89 \%$ overall accuracy, which is within the threshold of not less than $75 \%$ accuracy according to the literature for assessing image classifi- cation in the tropics. The accuracy of the 1990 land use map could not be assessed because of non-availability of field data but was based on the 2009 aerial photographs and 2010 land use map.

\section{Land use and land use change analysis}

The land use and land cover change analysis were performed to know changes in terms of spatial extent, trend and trajectory of the various land use classes within the time frame. This was made possible by the use of post-classification change detection algorithm in ERDAS. Using union matrix tool in ERDAS Imagine, the 1990 and 2010 land use maps were used as input data sets to generate land use change (LUC) map and a report of change matrix generated for the 20 -year period. The 1990-2010 change matrix generated showed the amount of change in terms of area in hectares and percentage as well as land use conversion and change trajectory for the period.

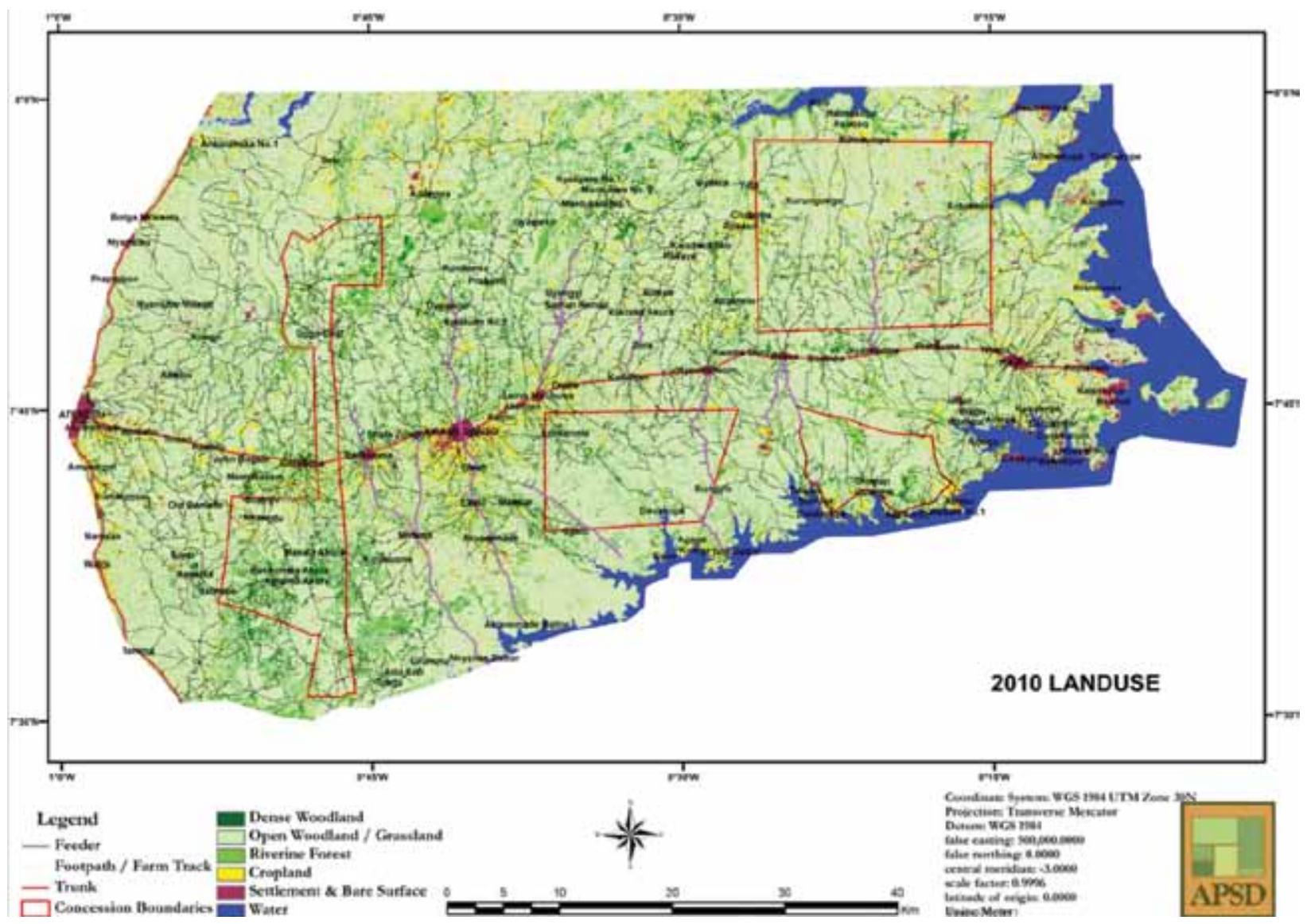

Figure 4. Land Use Map 


\section{Results}

\section{Land use map2010}

The land use map for 2010 epoch (Fig. 4) shows six main land use categories: dense woodland, open woodland, riverine forest, cropland, settlement and bare surface and water

\section{Open woodland}

The predominant class is open woodland and is little more than half of the total land area and is shown in light green in the map with even distribution in the study area.

\section{Dense woodland}

This is followed by dense woodland. It is found in patches across the study area. The dense woodland occur more in areas where there are fewer human settlements than in areas where there is higher concentration of settlement such as along the main roads. The basal area of woody species ranges from 5 to at least $20 \mathrm{~m}^{2} \mathrm{ha}^{-1}$, and this is very high in comparison to the open woodland, which has lower basal area of from 0.25 to $10 \mathrm{~m}^{2} \mathrm{ha}^{-1}$. The stem diameter varies from 5 to $25 \mathrm{~cm}$. However, there are few isolated big trees with diameter reaching $50 \mathrm{~cm}$ with large crowns and profuse branching. The undergrowth is mainly bush, brash and shrubs.

\section{Riverine/Riparian/Gallery forest}

The next vegetation class is the riverine/riparian/gallery forest that covers less than $2 \%$. It is the plant habitats and communities along the river margins and banks, which is the interface between the land and rivers/ streams. It occurs in strips and meanders along rivers or stream course.

\section{Cropland}

This land use class covers (8.6\%) of the total area, mainly annual crops such as maize, yam, vegetables, guinea corn and cassava. The yam and cassava farms occur within the open woodlands, and the cereals occur in the grasslands. The crop lands is mosaic of grassland and fallow areas. They occur around settlements and roads, an indication of human influence. There are, however, few farms occuring deep inside the study area. Freshly prepared croplands and fallow areas that have been burnt appear as bare surfaces. Charcoal burning occur in some areas of this land use.

\section{Settlement and bare surface}

This land use class covers 5,462 ha, thus $1.3 \%$ of the land surface of the study area, and is a reflection of the sparsely populated nature of the area. The built-up areas are made up of peri-urban, small towns, hamlets and farm settlements of 2-5 households. Rock outcrops, road surfaces, gravel pits and other surfaces without vegetation are also included in this class.

\section{Water}

This land use class has a spatial extent of 34,089 ha $(8.0 \%)$ of the study area, which comprises mostly the Volta Lake, rivers, river tributaries, dams and pools of water collected during the raining season.

\section{Landuse change}

The LUC in terms of area and percentage change is shown in Table 1. The table reveals that open woodland (disturbed, degraded areas) constitutes the most extensive land use category. It was expanded by 58,703 ha, $34.4 \%$ of its original size in 1990 and $14 \%$ of the total study area in 2010. Settlement and bare land expanded by 4,820 ha, thus $751 \%$ of its original areas in 1990 and $1 \%$ of the total land area in 2010, a reflection of the low population density in the area. Dense woodland lost 81,243 ha, which is $42 \%$ of its area in 1990 and $19 \%$ of the total land area of study area in 2010. Cropland expanded by 25,682 ha, which is $236 \%$ of its original area in 1990 and $6 \%$ of the total study area in 2010. Riparian

Table 1. Area Coverage of the Various Land Uses

\begin{tabular}{|l|r|r|r|r|}
\hline \multirow{2}{*}{\multicolumn{1}{|c|}{ Land use }} & \multicolumn{2}{|c|}{1990} & \multicolumn{2}{c|}{2010} \\
\cline { 2 - 5 } & $\begin{array}{c}\text { area } \\
\text { (ha) }\end{array}$ & area (\%) & $\begin{array}{c}\text { area } \\
\text { (ha) }\end{array}$ & area (\%) \\
\hline $\begin{array}{l}\text { Settlement/Bare } \\
\text { Surface }\end{array}$ & 642 & 0.2 & 5,462 & 1.3 \\
\hline Dense Woodland & 192,582 & 45.4 & 111,339 & 26.3 \\
\hline Open Woodland & 170,577 & 40.2 & 229,280 & 54.0 \\
\hline Riverine Forest & 22,753 & 5.4 & 7,746 & 1.8 \\
\hline Cropland & 10,869 & 2.6 & 36,551 & 8.6 \\
\hline Water & 27,044 & 6.2 & 34,089 & 8.0 \\
\hline Totals & 424,467 & 100.0 & 424,467 & 100.0 \\
\hline
\end{tabular}


vegetation was lost significantly by 15,007 ha, which is $66.0 \%$ of its original area in 1990 and $4 \%$ of the total land area of the study area.

The spatial extent of water increased by 7,045 ha, which represents $26 \%$ of its area in 1990 and $1.7 \%$ of the total study area, within the study period. The change in extent is attributed to seasonal flooding but not the number of water bodies in the area. Flood poses a serious environmental threat in the area that has to be carefully considered by the management of APSD.

\section{Land use conversion}

The change map, Figure 5, generated from the two thematic maps with the various land use conversions as indicated in the map. It can be observed visually that conversion to open woodland was dominant. Table 2 shows the LUC matrix and the area calculation of the land use conversion taking place in the study area for 1990-2010 epochs (20 years). This gives quantitative figures of the transfer/conversion of land use from one form to another. In Figure 5, the areas shown in grey are ash re-
Table 2. Area Change

\begin{tabular}{|c|c|c|c|c|c|}
\hline \multirow[b]{2}{*}{ Land use } & \multirow{2}{*}{$\begin{array}{l}1990 \\
\text { area } \\
\text { (ha) }\end{array}$} & \multirow{2}{*}{$\begin{array}{l}2010 \\
\text { area } \\
\text { (ha) }\end{array}$} & \multirow[b]{2}{*}{$\begin{array}{c}\text { Area } \\
\text { change } \\
\text { (ha) }\end{array}$} & \multicolumn{2}{|c|}{$\%$ change } \\
\hline & & & & 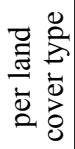 & 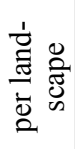 \\
\hline $\begin{array}{l}\text { Settlement/bare } \\
\text { surface }\end{array}$ & 642 & 5,462 & 4,820 & 751 & 1 \\
\hline Dense woodland & 192,582 & 111,339 & $-81,243$ & -42 & -19 \\
\hline Open woodland & 170,577 & 229,280 & 58,703 & 34 & 14 \\
\hline Riverine forest & 22,753 & 7,746 & $-15,007$ & -66 & -4 \\
\hline Cropland & 10,869 & 36,551 & 25,682 & 236 & 6 \\
\hline Water & 27,044 & 34,089 & 7,045 & 26 & 2 \\
\hline Totals & 424,467 & 424,467 & & & \\
\hline
\end{tabular}

mained unchanged for the period; these areas have been highlighted in yellow in Table 3 . The cells highlighted in green gives the totals of the land uses for the two time epochs, that is, 1990 and 2010. The last column indicates the net change, the negative sign represents the loss and

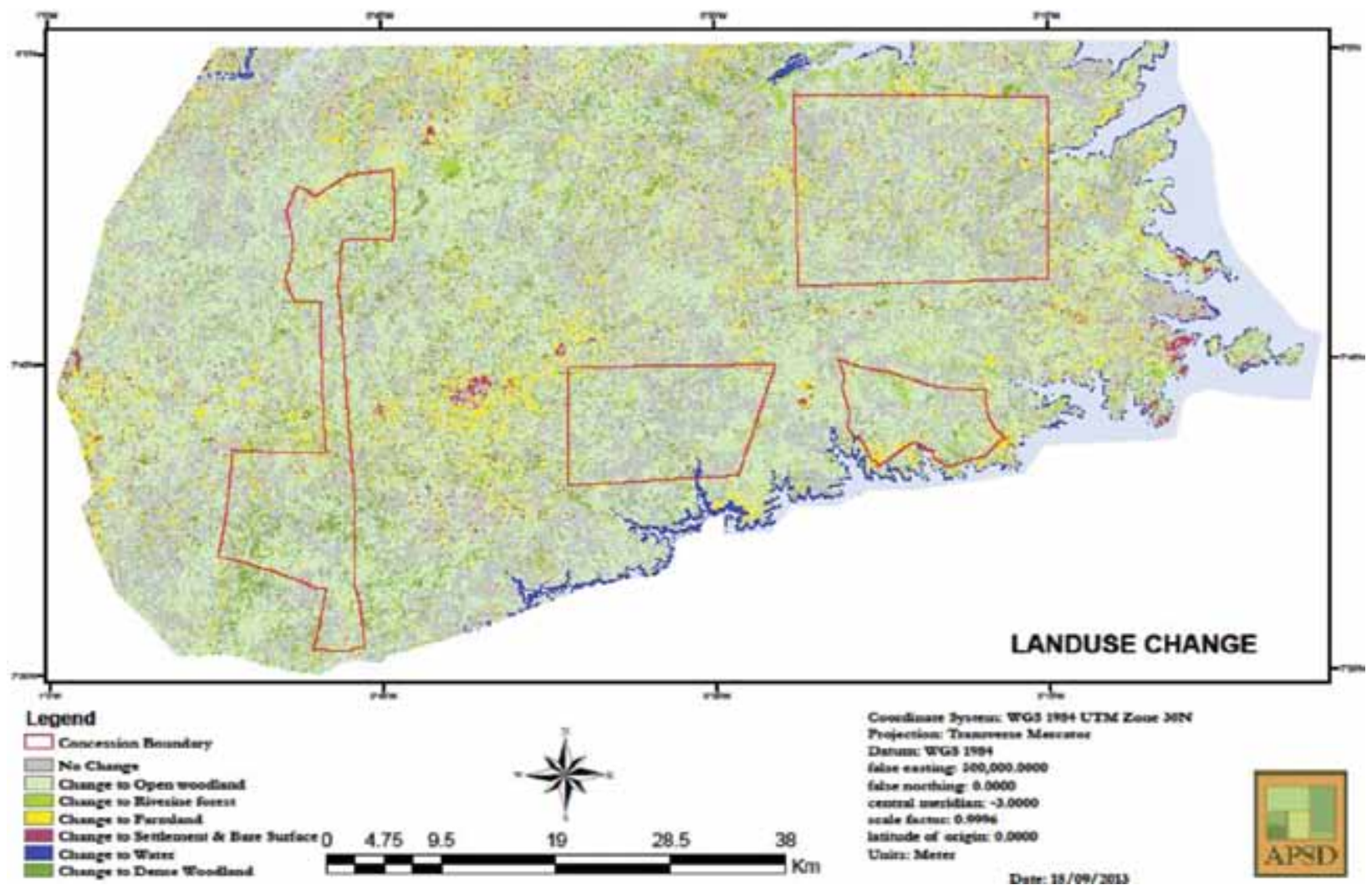

Figure 5. Land Use Change Map 
Table 3. Land Use Conversions

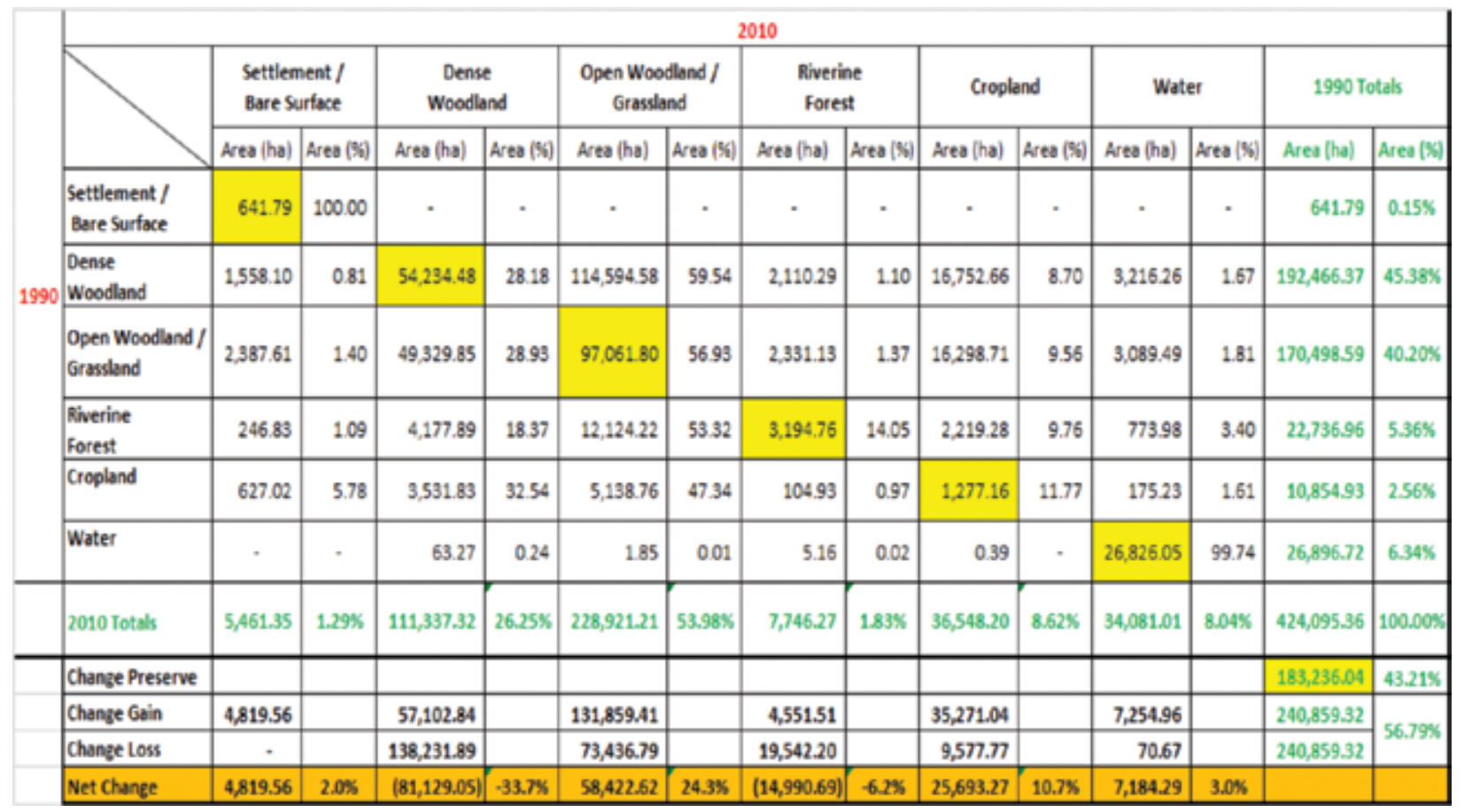

the positive sign represents the gain. Overall, $43 \%$ of the study area within the 20 -year period was preserved or did not change, whereas $57 \%$ of the area experiences conversion from one land use to another. If the businessas-usual scenario persists, then in next 20 years, all the natural landscape would have been lost.

\section{Discussion}

\section{Land use}

Land use maps are accepted worldwide as the basis for efficient and prudent utilisation of land ( $\mathrm{Li}$ and Liu 2017; Xie 2017). It is even more relevant where the inhabitants depend on the natural resources for their livelihoods (Blaikie and Brookfield 2015).

\section{Open woodland}

The open woodland is the transformation of the dense woodland as a result of charcoal production, farming activities, extensive and intensive timber harvesting, over grazing and annual bushfires (Agyemang and AbdulKorah 2014; Onak 2015). It forms a transition between the dense woodlands and agriculture and grassland, and this makes it a critical ecological transitional zone that extensively covers and forms more than $60 \%$ of the land surface of the study area. This area has a potential of transforming the entire landscape from open woodland to grassland if not properly managed. High population has led to high demand for wood and wood products, expansion of agricultural lands using shifting cultivation and fast urbanisation as a result of creating new districts leading to expansion in infrastructure. The expansion of the open woodland is attributed to these social and economic changes that are currently occurring (Koranteng et al. 2017). Yanda and Mubaya (2011) reaffirmed that a loss in productivity of land will adversely affect the livelihood of the fringe local populace who rely on natural resources for a subsistence lifestyle.

\section{Dense woodland}

This is naturally occurring vegetation cover that exists in patches within the study area. According to the recent carbon assessment studies (Unpublished Ghana Forest Preservation Programme 2012), the dense woodland holds an estimated $50-80 \%$ of carbon stock in the area and has diverse plant and animal species that contributes to more than $70 \%$ of the biodiversity 
resources. This finding is supported by a research by Malmer (2007) on general ecological features of Miombo woodlands and considerations for utilisation and management in Malawi. The area is generally very flat and abounds in surface water as a result of the numerous rivers, streams and the Volta Lake draining the area, which often makes it prone to flooding. The dense woodland serves as receptacle for holding the excess water and preventing flooding. The destruction of the dense woodland will obviously have serious environmental impacts on the carbon pools and leads to conversion of biomass into greenhouse gases. This often results in social consequences such as loss of hunting grounds and soil fertility, which lead to decline in the productivity of the land and invariably affects the food production.

Again, deforestation as a result of indiscriminate and illegal timber harvesting in recent times have contributed significantly to the destruction and fragmentation of the dense woodland, which has led to the loss of habitat and breeding grounds and isolation of native and indigenous species. There are reported cases of sacred areas such as grooves and burial ground that are being destroyed by timber merchants and this affects the cultural and religious beliefs of the people. The study revealed that more than $70 \%$ of the population within the study area still depend on herbal medicine for their health needs, and the dense woodland has majority of its composition being a medicinal plants for the people as well as providing habitat for the few fauna within the area.

Charcoal production is intensive and extensive in the study area and has contributed to the degradation of the dense woodland. Wood fuel account for more than $60 \%$ of the total energy used in Ghana and is the traditional energy source with the bulk of the country's primary energy source coming from wood biomass with an estimated annual consumption of 14-16 million tonnes (GSS 2013). The transitional and savannah woodlands are reported to be the major sources of wood fuel and mostly preferred by most Ghanaian. This makes the area very vulnerable to the effects of charcoal production. Wood harvesting for charcoal production has depleted and fragmented the dense woodland, changing its original state and diversity and contributing significantly to greenhouse gas emissions that affect global warming and climate change.
For the 20-year period, the woodland was reduced by $19 \%$ of the total land area and $73 \%$ of its original size in 1990, which means that in the next 20 years, if the 'business-as-usual' scenario persists, the dense woodland would have been lost significantly and the resultant effect will affect the biodiversity resources, render the area prone to flooding and decrease food production and economic activities of the people. This will negatively impact the carbon stocks and supply of wood and wood resources to the rural communities. Furthermore, fragmentation of the dense woodland will lead to habitat fragmentation, which often results in isolation of species and loss of breeding ground for species, which will adversely affects biodiversity. The results shows that the dense woodland in the study area has become ecologically threatened and need some level of protection to ensure that the remnants are sustainability managed for future generations.

\section{Riparian vegetation}

Riparian zones, which are natural vegetation occurring along streams, rivers and some wetlands, are getting depleted fastly. Within the 20 -year period, this category lost $66 \%$ of its original size in 1990 and $4 \%$ of the total land surface of the study area. This means that substantial area of the riparian vegetation in the study area has completely lost its vegetation. As revealed by this study, more than $90 \%$ of the people depend on surface and underground water for survival. The underground water is being recharged by the numerous streams and rivers that drain the area. The streams and rivers are protected by the riparian vegetation. Vegetable cultivation around these water bodies is very common in the dry season, and farmers apply fertilisers and other agro-chemicals that may be washed into the streams and pollute the water bodies. Research has shown that riparian zones are instrumental in water quality improvement for both surface runoff and water flowing into streams through subsurface or groundwater flow. These zones are important as they act as natural biofilters for this underground and surface water. Furthermore, riparian vegetation protects aquatic environments, supply shelter and food for many aquatic animals and also provides shade that protects and regulates the stream temperature.

Some of the riparian areas have specific cultural significance such as the crocodile ponds in Kyeamek- 
rom and Menko. The study area shares boundaries with the Digya National Park (Southeast of the area, across the Volta Lake, approximately $2 \mathrm{~km}$ ), which has diverse wildlife resources. The riparian zones in the Southern part of the area provide corridors that enable fauna from the National Park to move to the project area. The riparian vegetation provides forage for wildlife and livestock, which was observed in large numbers within the study area. This zone is the most threatened vegetation zone and must be given serious attention.

\section{Cropland}

The study has confirmed that agriculture is the main stay of the people in the study area and crops grown are mainly annual such as yam, maize, rice, cassava, groundnut, beans and vegetables. The average farm size is about 2 ha and most farmers still rely on hoe and cutlass for tilling the land. Traditionally, tree and cash crops such as cocoa, citrus and oil palm are not grown, although there are few patches of teak, mango and cashew plantation found in the area. The results show that cropland expanded by $70 \%$ of its size during the 20 -year period and $6 \%$ of the total landscape. This fact is supported by the 2010 Population and Housing Census of Ghana. From 1990 to 2010, the population of the area especially Atebubu and Kwame Danso has more than doubled. This invariably accounted for the dramatic increase in the open woodlands where the farms are located and corresponding decrease in the dense woodland that is being converted to farms.

It is important to state that there is high population of migrant farmers who are granted user rights to communal lands within some tenure arrangements with landowners. Owing to slash and burn farming practice, wildfires are rampant in these areas and this has contributed significantly to transforming the vegetation cover of the area. The slash and burn method of farming and its resultant bushfires pose a serious threat to plantation development. A concise Wildfire Management Plan is required to manage the bushfires in the area.

\section{Settlement and bare surface}

The study areas fall within the Afram plains enclave of the Brong Ahafo Region, which has the lowest population density in Ghana, and the land use map characteristically confirms the settlement pattern. It is interesting to note that the towns are, however, expanding at an alarming rate as shown in the LUC map. From the result presented in Table 2, settlement, which includes road surfaces, gravel pits and human habitation, was expanded by $751 \%$ of its original size in 1990 and $1 \%$ of the total land surface in the study area. This shows that human settlement is expanding very fast because of urbanisation, but the expansion is not commensurate with the vast expanse of land so the area still remains sparsely populated.

The settlements are generally hamlets, small communities and towns that constitute $70 \%$ of the class and few urban settlements. Aside human settlements, the results of the study has revealed the existence of patches of bare surface because of sand winning activities for road construction, which forms the other component of these land use. Most of the houses are constructed with mud and mud bricks that are poorly built with weak foundation and poor drainage system. In the hinterlands, the houses can best be described as farm huts roofed with thatch, and the communities lack electricity, schools and health facilities. Also the road network is terribly bad, and some of the areas remain flooded in the rainy season. The bad state of road networks has serious implication on tree plantation development and any other commercial activities. However, the low population and limited settlement makes the area suitable for commercial plantation.

\section{Water}

From the results, the source of water includes the Volta Lake, perennial rivers, streams and ponds. This class remains generally stable but varies seasonally. The area is generally flat with iron pans in the northern parts bordering the Volta Lake. The underlying rocks are impervious to water; therefore, rain water tends to remain on the surface resulting in intermittent flooding. Pools of water are collected in the low lying areas in the rainy season and dries up in the dry season.

\section{Land use conversions}

Land use change matrix provides a comprehensive data set in terms of the overall landscape, the types and extent of changes and the change trajectory, which have occurred (Hermosilla et al. 2015; Prestele et al. 2017). From Table 3, about 183,236.04 ha (43\%) of the total study area experienced no change as shown diagonally and highlighted yellow in the change matrix. 
A total of $24,0859.32$ ha $(57 \%)$ of the landscape experienced various forms of conversions. A net gain of $24.3 \%$ equivalent to $58,422.62$ ha was converted to open woodland. From Table 3, it reveals that dense woodland and riverine contributed the most to this gain. Dense woodland and riverine forest contributed $50 \%$ and $5 \%$, respectively, to the gain in open forest. These conversions have far reaching consequences for biodiversity, carbon emission and loss of carbon sinks, which negatively impacts the climate. Settlement and bare sure surface gained $4,819.56$ ha $(2 \%)$ from open woodland and cropland. Settlement and bare areas gained 4,819.56 ha from dense woodland and open woodland. This is inferred from the results because of the dramatic increase in population and urbanisation, which often leads to the destruction of natural resources for infrastructural development.

It is observed that cropland gained (10.7\%) predominantly from open and dense woodlands. Furthermore, conversion of the woodlands to cropland will drastically change natural internal nutrient cycling and nutrient loss will exceed nutrient gain, consequently affecting the productivity of the land. This is so because farming is the predominant occupation of the people over the period, and the dramatic increase in population has resulted in high demand for food and, consequently, the expansion of farms.

Water increased by $3 \%$, and this increase is attributed to the existence of numerous rivers and the Volta lake that drains the area and gets flooded as a result of clearing the vegetation along the water bodies. Heavy siltation of the rivers has resulted in some of the river beds exposed during the dry season and very conducive for vegetable farming because of the high soil fertility and moisture in the dry season.

\section{Conclusion}

The study has revealed that within the past 20 years, about $56.79 \%$ of land use was converted from one form to another, whereas $43.21 \%$ remains unchanged, and this means that more of the area is converted than preserved, and, consequently, in the next 20-40 years, if the business-as-usual scenario remains, then the area will lose all its natural landscape. It has been revealed that within the 20-year period, dense woodland and riverine forest had net loss of $33.7 \%$ and $6.2 \%$, respectively, whereas settlement, open woodland, cropland and water had a net gain of $2 \%, 24.3 \%, 10.7 \%$ and $3 \%$, respectively.

The riverine areas are highly degraded and the study did not find any stretch of continuous vegetation along the rivers that met the World Wide Fund for Nature (WWF) and Forest Stewardship Council (FSC) standards. The dense natural vegetation occurs in small patches and fall within private lands that might be difficult to conserve. In addition, the extent was quite small and very prone to wood fuel harvesting. The island communities are far away from the concession, and the study did not find anything unique within these communities.

The two crocodile habitats at Menkor and Kyeamekrom are areas worth conserving and developing into ecotourism sites. These habitats are also located far from the concession, and the District Assemblies, traditional authorities and communities should play the lead role in conserving these areas; however, APSD could support the assemblies.

The traditional bush-fallow system of cultivation that involves the slashing and burning of forests and grasslands has led to an increased loss of wildlife and wildlife habitats. Much of the newly cropped land is unsuitable for agriculture and degrades quickly, thereby forcing the farmer to convert even more land to agriculture.

Against the background of the findings and conclusions, the following recommendations are being made for consideration by APSD:

1. Indigenous species and remnants natural woodland should be retained within the plantation, these are found to have important value as habitat for a wide range of species such as birds, mammals, reptiles and other taxa. Moreover, a landscape mosaic consists of stands of plantation trees and remnant patches of native vegetation will support significantly higher levels of native taxa than plantation landscapes that are monocultures.

2. Native vegetation along gully lines should be protected because these areas can be valuable dispersal routes for some species (e.g. small terrestrial native mammals). These areas are also often quarantined from plantation establishment for quality reasons and might be useful places to target for native vegetation restoration efforts. 


\section{Acknowledgement}

Authors acknowledge the invaluable contributions of Mr. Yakubu Mohammed and Mr. Emmanuel Donkor (RMSC - Forestry Commission, Ghana), Resource Conservation Initiative and African Plantation for Sustainable Development (APSD) Gh Ltd.

\section{References}

Agyemang, I., Abdul-Korah, R. 2014. Strategies to combat desertification in Northern Region of Ghana: The role of Environmental Protection Agency. Physical Sciences Research International, 2 (2), 35-43.

Barlow, J. et al. 2018. The future of hyperdiverse tropical ecosystems. Nature, 559 (7715), 517.

Blaikie, P., Brookfield, H. 2015. Land degradation and society. Routledge.

Brown, C., Ball, J. 2000. World view of plantation grown wood. Oceania, 2, 0-01.

Carnus, J. et al. 2003. Planted forests and biodiversity. Paper Presented at UNFF Intersessional experts Meeting on the Role of planted forests in sustainable forest management, 24 - 30 March, New Zealand.

FAO. 2010. Global forest resources assessment 2010. Food and Agriculture Organization of the United Nations, Rome.

FAO. 2011. State of the world's forests 2011. Food and Agriculture Organization of the United Nations, Rome.

FAO. 2015. State of the world's forests 2015. Food and Agriculture Organization of the United Nations, Rome.

GSS. 2013. 2010 Population and housing census national analytical report. Accra, Ghana.

Hermosilla, T., Wulder, M.A., White, J.C., Coops, N.C., Hobart, G.W. 2015. Regional detection, characterization, and attribution of annual forest change from 1984 to 2012 using Landsat-derived time-series metrics. Remote Sensing of Environment, 170, 121-132.

Koranteng, A., Adu-Poku, I., Zawiła-Niedźwiecki, T. 2017. Drivers of land use change and carbon mapping in the savannah area of Ghana. Folia Forestalia Polonica, Series A - Forestry, 59 (4), 287-311.
Lele, U.J. 2017. Managing a global resource: challenges of forest conservation and development. Routledge.

Li, Y., Liu, G. 2017. Characterizing spatiotemporal pattern of land use change and its driving force based on GIS and landscape analysis techniques in Tianjin during 2000-2015. Sustainability, 9 (6), 894.

Li, Y., Chen, J., Rao, Y. 2018. A practical sampling method for assessing accuracy of detected land cover/land use change: Theoretical analysis and simulation experiments. ISPRS Journal of Photogrammetry and Remote Sensing, 144, 379-389.

Malmer, A. 2007. General ecological features of Miombo woodlands and considerations for utilization and management. Proceedings of the First MITMIOMBO Project Workshop held in Morogoro, Tanzania, 6th-12th February 2007. MITMIOMBO - Management of Indigenous Tree Species for Ecosystem Restoration and Wood Production in Semi-Arid Miombo Woodlands in Eastern Africa, 34-42.

Onak, T.T. 2015. The causes and consequences of deforestation on woodlands production in the central clay plains of the Sudan: A case study of ErRenk Area (doctoral dissertation, UOFK).

Paquette, A., Messier, C. 2010. The role of plantations in managing the world's forests in the Anthropocene. Frontiers in Ecology and the Environment, 8 (1), 27-34.

Prestele, R. et al. 2017. Current challenges of implementing anthropogenic land-use and land-cover change in models contributing to climate change assessments. Earth System Dynamics, 8 (2), 369-386.

Stephens, S.S., Bosu, P.P., Wager, M.R. 2016. Effect of overstory tree species diversity and composition on ground foraging ants (Hymenoptera: Formicidae) in timber plantations in Ghana. International Journal of Biodiversity Science, Ecosystem Services and Management, 12 (1/2), 96-107. https://doi.org/1 $0.1080 / 21513732.2016 .1158209$

Tims, W. 2009. GIS Model for the land use and development master plan in Rwanda.

Xie, H. 2017. Towards sustainable land use in China: A collection of empirical studies.

Yanda, P.Z., Mubaya, C.P. 2011. Managing a changing climate in Africa: Local level vulnerabilities and adaptation experiences. African Books Collective. 